\title{
Correction to: Robot 2019: Fourth Iberian Robotics Conference
}

\author{
Manuel F. Silva, José Luís Lima, Luís Paulo Reis (D), \\ Alberto Sanfeliu, and Danilo Tardioli
}

\section{Correction to:}

M. F. Silva et al. (Eds.): Robot 2019:

Fourth Iberian Robotics Conference, AISC 1092,

https://doi.org/10.1007/978-3-030-35990-4

The original version of the book was inadvertently published with incomplete information in the Organization page of the front matter, which has now been included. The book has been updated with the change. 